\title{
Perfil das intoxicações exógenas por agrotóxicos de uso agrícola
}

\section{Profile of exogenous poisonings by agrotoxics for agricultural use}

\author{
Eliane Frizon ${ }^{1}$, Simone Domingues Garcia ${ }^{2}$, Dulce Maria Strieder ${ }^{3}$, \\ Taynah Ivanir da Costa de Lara ${ }^{4}$
}

\begin{abstract}
Resumo
Objetivo: apresentar o perfil das intoxicações exógenas por agrotóxicos de uso agrícola. Trata-se de um estudo retrospectivo, que correspondeu ao período de janeiro de 2007 a dezembro de 2015, descritivo, com elementos epidemiológicos de análise quantitativa e cunho documental. Para a análise utilizou-se dados das fichas de investigação disponíveis na base de dados DATASUS. De acordo com os dados analisados a faixa etária mais acometida por intoxicação devido ao uso de agrotóxicos foi a de 20 a 49 anos, sendo os principais casos acidentais e por tentativas de suicídio. A população acometida possui baixo grau de escolaridade e a principal via de intoxicação foi a via digestiva, seguida pela respiratória e cutânea. Conclui-se que a intoxicação pelo uso dos agrotóxicos precisa ser avaliada como um grave problema da saúde pública, uma vez que acomete não apenas a saúde do trabalhador, mas o meio ambiente e a comunidade.
\end{abstract}

Palavras-chave: Saúde do trabalhador. Agrotóxicos. Intoxicações. Saúde pública. Enfermagem. Enfermagem em saúde pública.

\begin{abstract}
Objective: to present the profile of exogenous intoxications by agricultural pesticides. This is a retrospective study, wich corresponded to the period from january 2007 to december 2015, descriptive, with epidemiological elements of quantitative analysis and documentary nature. For the analysis data from the research forms available in the DATASUS database were used. According to the data analyzed the age group most affected by intoxication due to the use of pesticides was 20 to 49 years, the main cases being accidental and due to suicide attempts. The affected population has low level of education and the main route of intoxication was to the digestive route, followed by respiratory and cutaneous. It is concluded that intoxication by the use of pesticides needs to be evaluated as a serious public health problem, since it affects not only the health of the worker, but the environment and the community.
\end{abstract}

Keywords: Worker's health. Pesticides. Intoxications. Public health. Nursing. Nursing in public health.

${ }^{1}$ Especialização em Saúde do Trabalhador pela Fundação Oswaldo Cruz (Fiocruz). Enfermeira da Prefeitura Municipal de Cascavel e Regional de Saúde, Cascavel, Paraná, Brasil.

${ }^{2}$ Doutoranda em Educação em Ciências e Educação Matemática na Universidade Estadual do Oeste do Paraná (Unioeste), Cascavel, Paraná, Brasil. Docente do Curso de Enfermagem da Universidade Estadual do Oeste do Paraná, Cascavel, Paraná, Brasil. E-mail: sidomingues@yahoo.com.br

${ }^{3}$ Doutorado em Educação pela Universidade de São Paulo (USP), São Paulo, Brasil. Professora Associada da Universidade Estadual do Oeste do Paraná, Cascavel, Paraná, Brasil.

${ }^{4}$ Graduanda em Enfermagem na Universidade Estadual do Oeste do Paraná, Cascavel, Paraná, Brasil. 


\section{Introdução}

Hoje o Brasil ocupa uma posição de destaque em produção agrícola direcionada à monocultura. O modelo agrícola adotado no País está voltado ao uso de agrotóxicos e produção em larga escala, ao considerar que a agricultura brasileira se centra em um modelo de desenvolvimento voltado a ganhos de produtividade. ${ }^{(1)}$

Em 2008, o País utilizou 673.862 toneladas de agrotóxicos, dos quais o Paraná participou com aproximadamente 100 mil toneladas, equivalendo à utilização de 12 quilos de agrotóxico por hectare ao ano, enquanto a média brasileira de consumo é de quatro quilos/hectare/ano. Os agrotóxicos utilizados no Estado são considerados "muito perigosos" e "perigosos", em uma classificação que vai de "pouco" a "altamente perigoso".(2)

Devido à sua alta atividade biológica e, em alguns casos, à sua persistência no ambiente, os agrotóxicos podem causar efeitos indesejáveis à saúde e ao ambiente. Seu manuseio inadequado pode resultar em intoxicações agudas e, às vezes, em efeitos de longo prazo, como as intoxicações crônicas causadas pela exposição a baixos níveis de agrotóxicos por um longo período. ${ }^{(3)}$

Dados do Sistema de Informação de Agravos de Notificação (Sinan), do Ministério da Saúde, apresentam, no período de 2007 a 2015, registro médio anual de 740 casos de intoxicação por agrotóxicos no Brasil, sendo 98,7\% deles de intoxicações agudas e 1,3\% crônica. ${ }^{(4)}$

No Brasil, as intoxicações por agrotóxicos estão entre os principais problemas de saúde pública que afetam diretamente a saúde do trabalhador, e representam um problema de saúde pública mundial, envolvendo principalmente países em desenvolvimento. ${ }^{(3)}$

Como exemplo de substâncias intoxicantes ambientais, há o ar, água, alimentos que sofreram influência de produtos tóxicos, plantas e animais peçonhentos ou venenosos. Por sua vez, os principais representantes de substâncias isoladas são os pesticidas, os medicamentos e produtos químicos industriais ou de uso domiciliar.
Os impactos com o meio ambiente e para a saúde humana têm sido negligenciados, e a contaminação dos recursos ambientais passa a ser uma ameaça à qualidade de vida das gerações futuras. ${ }^{(5)}$

Diante desse fato e do panorama mundial da utilização dos agrotóxicos, sendo o Brasil um dos maiores consumidores mundiais destes produtos, e o Paraná o estado que mais se destaca em número de casos registrados de intoxicações, este trabalho tem por objetivo apresentar o perfil das intoxicações exógenas por agrotóxicos de uso agrícola em um município da Região Oeste do Paraná no período de 2007 a 2015.

\section{Material e Método}

Trata-se de estudo retrospectivo, descritivo, de análise quantitativa e cunho documental, com a utilização de elementos que se aproximam de um estudo epidemiológico, realizado em um município do Oeste do Paraná.

As fontes de dados utilizadas foram as fichas de investigação, que se encontram disponíveis na base de dados DATASUS - Departamento de Informática do Sistema Único de Saúde, de pacientes que sofreram intoxicações por agrotóxicos de uso agrícola durante o período de janeiro de 2007 a dezembro de 2015. ${ }^{(6)}$

Foram coletados da ficha de investigação dados como gênero do paciente, idade, escolaridade, zona de residência, circunstância da exposição, se a exposição foi decorrente do trabalho e evolução do caso.

O estudo justifica-se nessa Região por ser uma área de predomínio do agronegócio, com extensas regiões de monocultura. É considerado um dos maiores polos econômicos da Região Sul do Brasil, e o sexto maior PIB do Paraná. O município diferencia-se por possuir uma lei municipal referente à utilização dos agrotóxicos em que expõe que é vedado o uso e aplicação de qualquer tipo de agrotóxico nas proximidades dos seguintes estabelecimentos na área rural do Município de Cascavel: escolas e colégios; Centros Municipais de Educação Infantil - CMEIs; Unidades Básicas 
de Saúde - UBSs; Unidades de Saúde da Família USFs e núcleos residenciais da área rural. ${ }^{(7)}$

Quando se trata de análise quantitativa os resultados são obtidos por meio de investigações, através das quais se obtém informações numéricas. Estas informações serão apresentadas por meio de quadros, tabelas e medidas. A pesquisa quantitativa trata com números, usa modelos estatísticos para explicar os dados. ${ }^{(8)}$

Os estudos retrospectivos observam o que aconteceu no passado, os indivíduos são seguidos do "efeito" para a "causa", ou seja, investigam acontecimentos, processos e instituições do passado, para verificar sua influência no presente. Ocorre um resgate da ficha de pacientes e se verificam acontecimentos do passado que possam ter influenciado na doença. ${ }^{(8)}$

Todos os casos notificados de intoxicação por agrotóxico de uso agrícola que ocorreram durante o período de janeiro de 2007 a dezembro de 2015 foram incluídos na pesquisa, e este foi o único critério de inclusão.

A análise dos dados foi realizada por estatística simples, utilizando o software Microsoft Office Excel 2013, utilizando apenas o cálculo de frequência relativa. A apresentação dos resultados foi realizada de forma descritiva e por meio de tabelas, discutindo-os.

Todos os dados são de domínio público, não necessitando, portanto, de aprovação do Comitê de Ética para a realização do estudo.

\section{Resultados e Discussão}

Durante o período de estudo foram identificadas 170 fichas de investigação de intoxicação exógena no sistema DATASUS. Verificou-se das fichas que 133 pessoas, correspondendo a $78 \%$, eram do sexo masculino e 37 pessoas, correspondendo a $22 \%$, eram do sexo feminino. Quanto à raça, observou-se que 48 pessoas, correspondendo a $28,24 \%$, eram da raça parda; 17 pessoas, correspondendo a $10 \%$, eram da raça branca; três pessoas, correspondendo a $1,76 \%$, eram da raça negra; e uma pessoa, correspondendo a $0,59 \%$, era indígena. A maior parte das pessoas não declarou raça: 101 pessoas, o que corresponde a 59,41\%.

No que se refere à idade dos pacientes, a faixa etária com maior número de ocorrências de intoxicações exógenas foi a de 40 a 49 anos, com 42 pessoas, o que corresponde a $24,71 \%$. Segue a faixa etária de 20 a 29 anos, com 35 pessoas, o que equivale a $20,59 \%$, e de 30 a 39 anos, com 34 pessoas, correspondendo a $20 \%$. Salienta-se que estas faixas etárias correspondem à população ativa, que compreende os trabalhadores que exercem função importante na economia do País e estão em idade reprodutiva, fator preocupante e que necessita de maior conhecimento, tanto do trabalhador quanto do empregador, para possíveis danos crônicos causados pela utilização dos agrotóxicos.

Tabela 1 - Dados sociodemográficos dos indivíduos notificados na ficha de investigação de intoxicações por agrotóxicos de uso agrícola em município do Oeste do Paraná.

\begin{tabular}{llc}
\hline Dados sociodemográficos & Números & Porcentagem \\
\hline \multirow{2}{*}{ Gênero } & Masculino (133) & $78,24 \%$ \\
& Feminino (37) & $21,76 \%$ \\
Raça & Parda (48) & $28,24 \%$ \\
& Branca (17) & $10,00 \%$ \\
& Negra (3) & $1,76 \%$ \\
& Indígena (1) & $0,59 \%$ \\
& Não declarada (101) & $59,41 \%$
\end{tabular}

Continua 
Continuação

\begin{tabular}{llc} 
Faixas etárias & Menores de 1 ano (2) & $1,18 \%$ \\
1 a 10 anos & - \\
11 a 19 anos & - \\
20 a 29 anos (35) & $20,59 \%$ \\
30 a 39 anos (34) & $20,00 \%$ \\
40 a 49 anos (42) & $24,71 \%$ \\
& Não declarada (57) & $34,7 \%$ \\
Zona de residência & Urbana (126) & $74,12 \%$ \\
& Rural (38) & $22,35 \%$ \\
& Não declarada (13) & $3,53 \%$ \\
\hline
\end{tabular}

Fonte: Ministério da Saúde ${ }^{(4)}$

Em outro estudo, as faixas etárias com maior predominância de pacientes intoxicados são as de 20 a 29 anos e de 30 a 39 anos, médias de idade dos trabalhadores em exercício no campo. As faixas etárias de um a quatro anos e cinco a nove anos são aquelas com maior ocorrência de intoxicados acidentalmente, o que ocorre também na área urbana, porém os agentes da intoxicação são outros. Em vez de inseticidas, herbicidas e fungicidas, na área urbana temos como fonte de intoxicações de crianças os produtos de limpeza como sabões, amaciantes, ceras e o álcool, armazenados de forma irregular e facilitando tais intoxicações acidentais. ${ }^{(9)}$

Os casos de intoxicação em crianças chamam atenção como um dado alarmante, já que demonstram a proximidade com substâncias tóxicas e a facilidade no acesso, o que representa falta de segurança referente aos mesmos. Ocorreram casos de intoxicação em pacientes menores de um ano, com duas notificações, correspondendo a $1,18 \%$. Segundo os dados colhidos, entre as crianças o agente tóxico predominante foram os raticidas e a circunstância foi o acidente individual. Considerase nessa faixa etária que a ingestão, mesmo em menor quantidade, apresenta alto risco de morte.

Como um fator diferencial, este estudo foi realizado em uma região de fronteira, o que alerta para o comércio ilegal e o uso indevido de praguicidas de uso agrícola, além das misturas presentes com outros produtos sem considerar o alto risco que envolve. Essa facilitação no acesso influencia que esses produtos sejam encontrados também em ambientes domésticos, expondo crianças e adolescentes ao risco de intoxicações graves.

Quanto à zona de residência dos pacientes envolvidos nas intoxicações, 126, correspondendo a $74,12 \%$, residiam na região urbana e 38 , correspondendo a $22,35 \%$, na zona rural.

Uma das hipóteses que poderia justificar o número maior de notificações na zona urbana é a presença de estrutura de serviços reconhecidamente melhores, além do acesso facilitado aos serviços de saúde, quando comparados aos da zona rural. Também se deve considerar que na área urbana a compreensão do que é caracterizado como agrotóxico é diferenciada, obtendo facilidade ao adquirir produtos denominados como "venenos domésticos" e que são classificados como inseticida ou raticidas, apresentando os mesmos riscos que os produtos utilizados na área rural.

Em estudo realizado na Paraíba, a média anual de intoxicações atingiu o patamar de 4.429 casos, o equivalente a $1,2 \%$ da população do estado; e no boletim nacional, o Sistema Nacional de Informações Tóxico-Farmacológicas (Sinitox) registrou 99.035 casos, o que equivale a $5,1 \%$ da população total. A Paraíba é um estado tipicamente urbano com predominância do gênero feminino, o que influenciou o perfil das intoxicações, já que a prevalência do gênero feminino foi observada $(56,14 \%)$, juntamente a uma população tipicamente 
urbana (87\%). Quanto ao perfil das intoxicações em nível nacional, observou-se uma pequena discrepância em relação ao Estado. No Brasil, os pacientes intoxicados são, na maioria, do gênero masculino, com prevalência da faixa etária de zero a quatro anos. ${ }^{(10)}$
O Gráfico 1 mostra que no município da Região Oeste do Paraná, em 58,82\%, 100 casos, as intoxicações ocorreram de forma acidental, em 27,64\%, 47 casos, se deram em função de tentativas de suicídio, e 7,65\%, 13 casos, ocorreram devido ao uso habitual de agrotóxicos.

Gráfico 1 - Circunstância da exposição dos indivíduos notificados na ficha de investigação de intoxicações por agrotóxicos de uso agrícola em município do Oeste do Paraná.

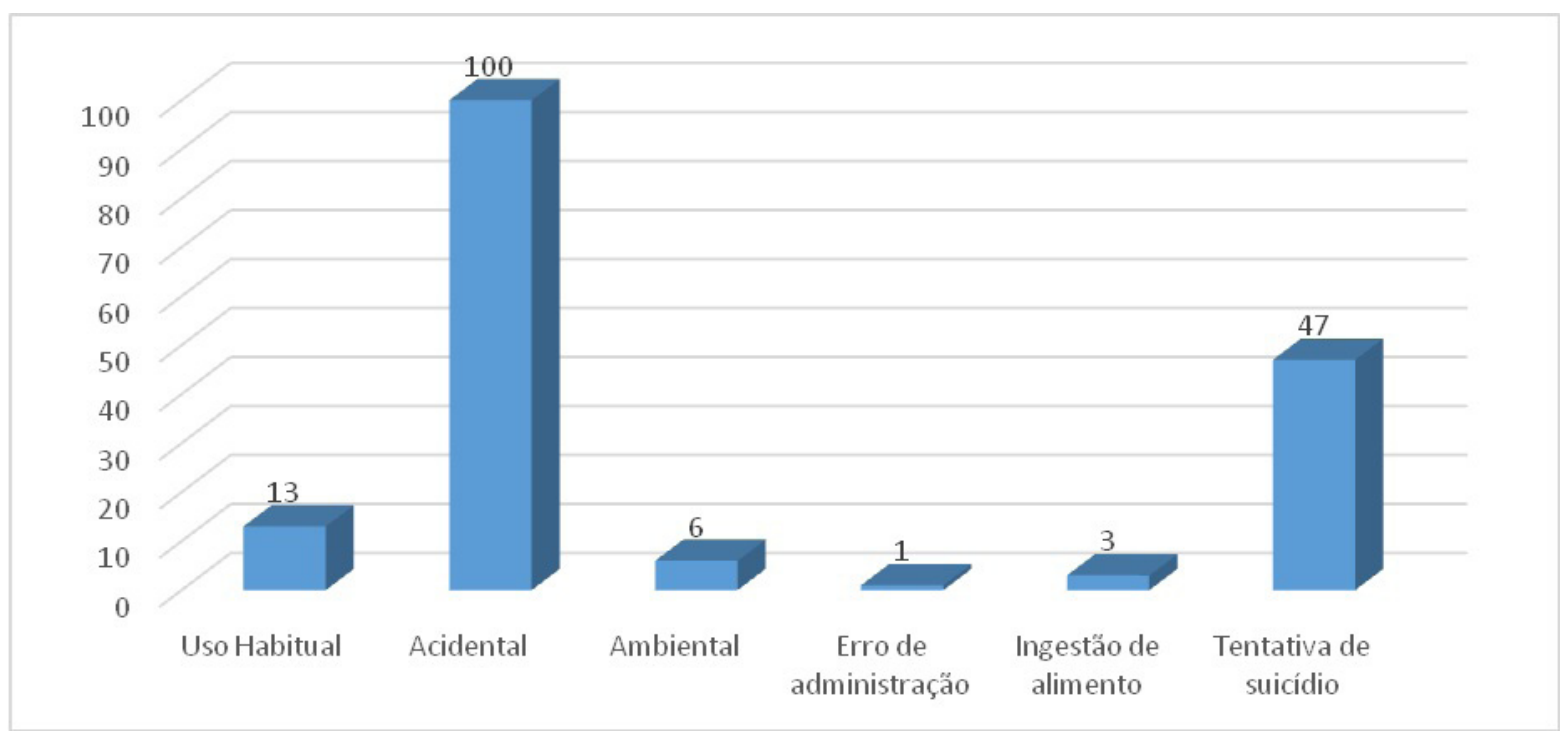

Fonte: Ministério da Saúde(4)

As intoxicações por exposição acidental podem ocorrer dentro das residências. Os agrotóxicos presentes nos ambientes domésticos utilizados para repelir insetos e artrópodes e para combater piolhos e outros parasitas podem proporcionar exposições acidentais, envolvendo principalmente crianças e idosos. Tais exposições são frequentemente ocasionadas devido à forma $\mathrm{e}$ locais incorretos de armazenamento, reutilização de embalagens dos agrotóxicos, derrame ao transportá-los, ou ainda pela ingestão involuntária de água e alimentos contaminados. ${ }^{(11)}$

Já nas exposições intencionais, como as tentativas de suicídio, além da possibilidade da exposição acidental dentro das residências, a disponibilidade destes produtos pode levar a casos de exposições intencionais, nos quais a pessoa faz uso de agrotóxicos, por qualquer via de introdução, com a finalidade de atentar contra a própria vida.
É a forma de intoxicação que atinge os mais altos índices de letalidade e nos alerta para as dificuldades encontradas na saúde mental da população em geral, como dos trabalhadores rurais. ${ }^{(11)}$

Em um estudo realizado na mesorregião Norte Central Paranaense, constatou-se que intoxicados do sexo masculino estão majoritariamente divididos entre intoxicações acidentais, por tentativa de suicídio e ocupacional. No sexo feminino as maiores incidências são por tentativa de suicídio (264 casos), com quase o dobro da segunda circunstância que mais atinge as mulheres, a circunstância acidental (130 casos) e, posteriormente, a circunstância ocupacional com 40 casos, e outros com 22 casos. ${ }^{(11)}$

Ao verificar o alto número de intoxicações por forma acidental é preciso existir questionamentos pelos profissionais e serviços de saúde, ao considerar que é preciso propor estratégias de 
acolhimento para a compreensão dos casos além dos números, para assim analisar qual a situação que estava sendo vivenciada durante o acidente, já que logo após essa porcentagem vemos o número de tentativas de suicídio.

Nossa exposição aos agrotóxicos é cotidiana, podendo ser de diferentes formas como: a contaminação ocupacional (trabalhadores rurais e camponeses que atuam diariamente com tais produtos desde a compra até o manuseio para a sua utilização), a contaminação alimentar (ingestão de alimentos contaminados com agrotóxicos, aos quais estamos todos expostos) e a contaminação ambiental, como o armazenamento e descarte incorreto, utilização em larga escala, mistura de diferentes produtos sem considerar os riscos expostos, proximidade com áreas de moradias e de criação de animais, além dos erros presentes em sua aplicação, entre outros. ${ }^{(12)}$

Assim, na análise das intoxicações por acidente de trabalho questiona-se as circunstâncias apresentadas nos ambientes de trabalho e a capacitação desses profissionais para o manuseio e utilização do produto, já que os trabalhadores rurais são responsáveis em muitos casos por todas as etapas, desde a compra até o armazenamento, preparo, manuseio e utilização. É notório que a exposição ao risco se estende a toda a família do trabalhador, devido os locais de armazenamento não serem distantes de suas casas, e, portanto, com comprometimento de todos os que interagem naquele ambiente.

Referente às formas de utilização do agrotóxico, ${ }^{(13)}$ o nível de capacitação dos operadores de máquinas destinadas à pulverização de agrotóxicos na Região Central do Rio Grande do Sul pode ser considerado baixo, com referência ao manejo correto dos processos de pulverização. Operadores que realizam cursos com mais de 20 horas de duração apresentam maior capacitação quando comparados aos que fazem cursos com carga horária menor que 20 horas; porém, mesmo estes ainda não possuem capacitação adequada no que se refere à escolha da taxa de aplicação e à regulagem dos pulverizadores.

Quanto à relação da intoxicação com atividade ocupacional, verifica-se na Tabela 2 que 74 casos, representando 43,53\%, estavam relacionados com trabalho, e 92 casos, representando 54,12\%, não estavam relacionados. No que se refere à atividade que estava sendo exercida no momento da exposição, em 60 casos, 35,29\%, ocorreram durante a pulverização do agrotóxico e em 18 casos, 10,58\%, ocorreram durante a diluição do agrotóxico.

Tabela 2 - Intoxicação relacionada ao trabalho dos indivíduos notificados na ficha de investigação de intoxicações por agrotóxicos de uso agrícola em município do Oeste do Paraná.

\begin{tabular}{lcc}
\hline Relação trabalho & FA & FR \\
\hline Ignorado & 4 & $2,35 \%$ \\
Sim & 74 & $43,53 \%$ \\
Não & 92 & $54,12 \%$ \\
Total & 170 & $100 \%$ \\
\hline
\end{tabular}

Fonte: Ministério da Saúde ${ }^{(4)}$

Referente à intoxicação relacionada ao trabalho, reconhece-se que a lógica associada na saúde do trabalhador a doenças e agravos em agricultores que manipulam agrotóxicos, costuma resultar da exposição a tais substâncias, chamando a isso de 'fator de risco'. Assim, escolhido um fator, como no caso as intoxicações, entre os que compõem o processo produtivo e estão implicados na produção dos agravos, ele será elevado à categoria de elemento causal, desconsiderando 
todo o peso determinante da estrutura produtiva. Esse raciocínio causalista esconde o fato de que as pessoas, como os trabalhadores rurais, têm liberdade restrita em seus 'estilos de vida' para se proteger dos processos destrutivos gerados pelo modo de vida no qual estão inseridos para a sua sobrevivência. ${ }^{(14)}$

A jornada de trabalho é um quesito indiscutível para compreensão da intensidade de exposição do trabalhador ao agrotóxico. Os trabalhadores participam quase que de todas as fases do processo que envolve os agrotóxicos, das atividades de mistura/preparação da calda, aplicação e lavagem do maquinário. Em quase todas as situações, normalmente quem aplica o produto - $87,49 \%$, prepara a calda e limpa o equipamento - $90 \%$ e $85 \%$, respectivamente. Com isso, tornam-se mais vulneráveis. ${ }^{(15)}$

Os trabalhadores também estão mais suscetíveis a exposições combinadas a agrotóxicos, área que apresenta muitas lacunas no conhecimento. Os estudos de toxicidade avaliam apenas a exposição a um ingrediente ativo isolado em animais de laboratório, com uma única via de exposição. No trabalho agrícola, porém, ocorrem exposições combinadas ou multiexposição a agrotóxicos. ${ }^{(14)}$

Tabela 3 - Via de exposição dos indivíduos notificados na ficha de investigação de intoxicações por agrotóxicos de uso agrícola em município do Oeste do Paraná.

\begin{tabular}{lcc}
\hline Via & FA & FR \\
\hline Ignorado & 6 & $3,53 \%$ \\
Digestiva & 69 & $40,59 \%$ \\
Cutânea & 28 & $16,47 \%$ \\
Respiratória & 64 & $37,65 \%$ \\
Ocular & 3 & $1,76 \%$ \\
Total & 170 & $100 \%$ \\
\hline
\end{tabular}

Fonte: Ministério da Saúde ${ }^{(4)}$

Em relação à via de exposição da intoxicação, a principal via observada na Tabela 3 foi a digestiva, verificada em 69 dos casos, representando 40,59\%. Seguiu-se a via respiratória, com 64 casos e 37,65\%. Logo após se verificou a via cutânea com 28 casos e $16,47 \%$. As vias digestiva e respiratória são as mais importantes quando se fala de intoxicação aguda, e a cutânea a mais importante na intoxicação crônica.

Ressalta-se que, a velocidade de aparecimento dos sintomas e a gravidade da intoxicação não dependem apenas da via de exposição, mas também de fatores relacionados com o agente intoxicante, às suas características químicas, como coeficiente de partição óleo/água, lipo ou hidrossolubilidade, e entre outras, à quantidade absorvida ou ingerida, tempo de exposição e às condições gerais de saúde da pessoa contaminada. ${ }^{(1)}$
Os sintomas das intoxicações agudas aparecem por um curto período. Podem ocorrer de forma leve ou grave, sendo dependente da quantidade de veneno absorvido, e os sinais e sintomas são nítidos e objetivos. Já as intoxicações crônicas são alterações no estado de saúde decorrente da interação contínua de uma substância tóxica com o organismo. Esse tipo de intoxicação produz efeitos danosos sobre a saúde humana, entre eles a acumulação de danos genéticos. Nessas condições os quadros clínicos são indefinidos, confusos e às vezes irreversíveis, e os diagnósticos são difíceis de serem estabelecidos. Por sua vez, a intoxicação crônica manifesta-se através de problemas imunológicos, hematológicos, hepáticos, neurológicos, malformações congênitas e tumores. ${ }^{(16)}$ 
A IARC (2015) - Agência Internacional de Pesquisa em Câncer, ligada à Organização Mundial da Saúde - classificou o glifosato, um dos agrotóxicos mais utilizados, podendo ser encontrado associado a outros tipos de agrotóxicos, como "provavelmente cancerígeno" após extensa revisão de publicações sobre o assunto. No Brasil, segundo o Instituto Nacional de Câncer, estimou-se para o biênio 2018-2019 a ocorrência de 600 mil casos novos de câncer, para cada ano. No Paraná, na Região Oeste, os registros aumentam a cada ano, relacionados à morbimortalidade provocada pelo câncer. ${ }^{(17)}$

Ao citar a escolaridade considera-se como um importante indicador, visto estar associado à condição social e pelo histórico brasileiro de analfabetismo no campo. $\mathrm{Na}$ análise dos dados do município do Oeste do Paraná, 40\% da amostra, 68 casos, não tinham o ensino fundamental completo e apenas 10,58\%, 18 casos, chegaram a concluir o ensino médio, como aponta o Gráfico 2.

Gráfico 2 - Escolaridade dos indivíduos notificados na ficha de investigação de intoxicações por agrotóxicos de uso agrícola em município do Oeste do Paraná.

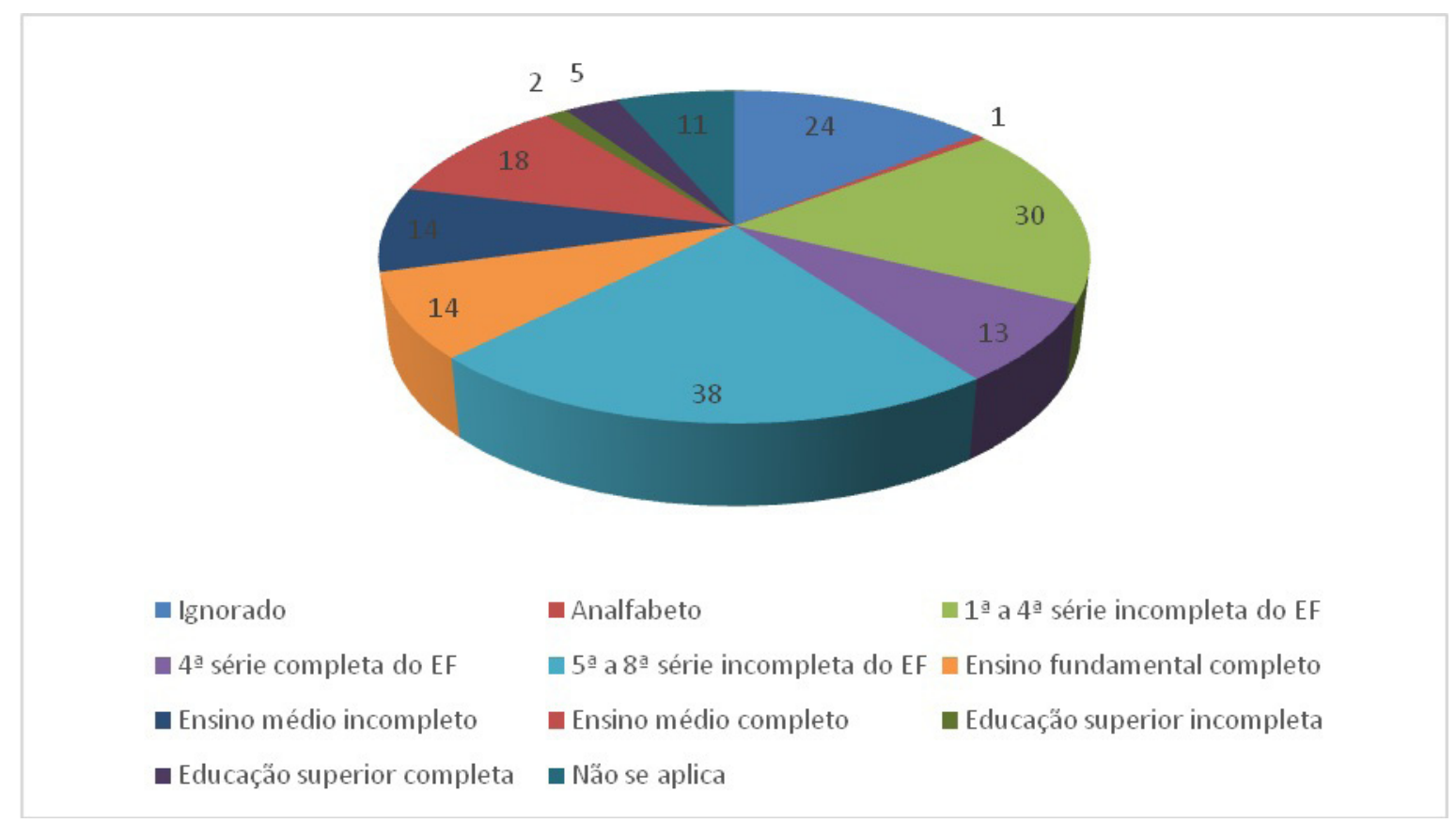

Fonte: Ministério da Saúde ${ }^{(4)}$

Em estudo com fumicultores, em relação à escolaridade, 75,7\% cursaram até a quarta série do ensino fundamental. Essas características são semelhantes às informações encontradas pela Pesquisa Nacional por Amostra de Domicílios com relação ao perfil da população rural economicamente ativa: $71 \%$ dessa população têm menos de 50 anos, e $75 \%$ apresentavam menos de 10 anos de estudo. ${ }^{(18)}$

A baixa escolaridade dos agricultores é um problema considerável, ao passo que isto dificulta a leitura de recomendações de segurança, do rótulo, e/ou ocasionalmente do receituário agronômico, da mesma maneira que limita o acesso a informações de segurança, além de fragilizá-lo frente à compreensão do contexto em que está inserido, tornando-se mero coadjuvante na realização de sua atividade laboral.

Com isso, afirma-se que a baixa escolaridade afeta diretamente a segurança desses trabalhadores, já que ao não conseguir compreender de forma clara os riscos expostos supõe-se que a atividade pode não ser considerada de alto risco, o que influencia tanto no seu processo de trabalho (uso 
incorreto de EPIs, contato direto com o produto, maior tempo de exposição, entre outros) como o seu modo de vida (armazenamento em local inadequado e aproximação com a moradia, fácil acesso ao produto por outros membros da família). Qualificar esses trabalhadores é fundamental, além da realização de um acompanhamento por profissional, como, por exemplo, um engenheiro agrônomo.
Ressalta-se que todas as ações propostas para redução de riscos são importantes, todavia, não excluem a necessidade de questionamento do uso abusivo de agrotóxicos.

Quando se trata de qual agrotóxico é o mais utilizado, observa-se que os herbicidas, seguidos dos inseticidas, são os mais utilizados, logo, são os que mais estão relacionados com intoxicações exógenas, como se pode observar do Gráfico 3.

Gráfico 3 - Tipos de agrotóxicos notificados na ficha de investigação de intoxicações por agrotóxicos de uso agrícola em município do Oeste do Paraná.

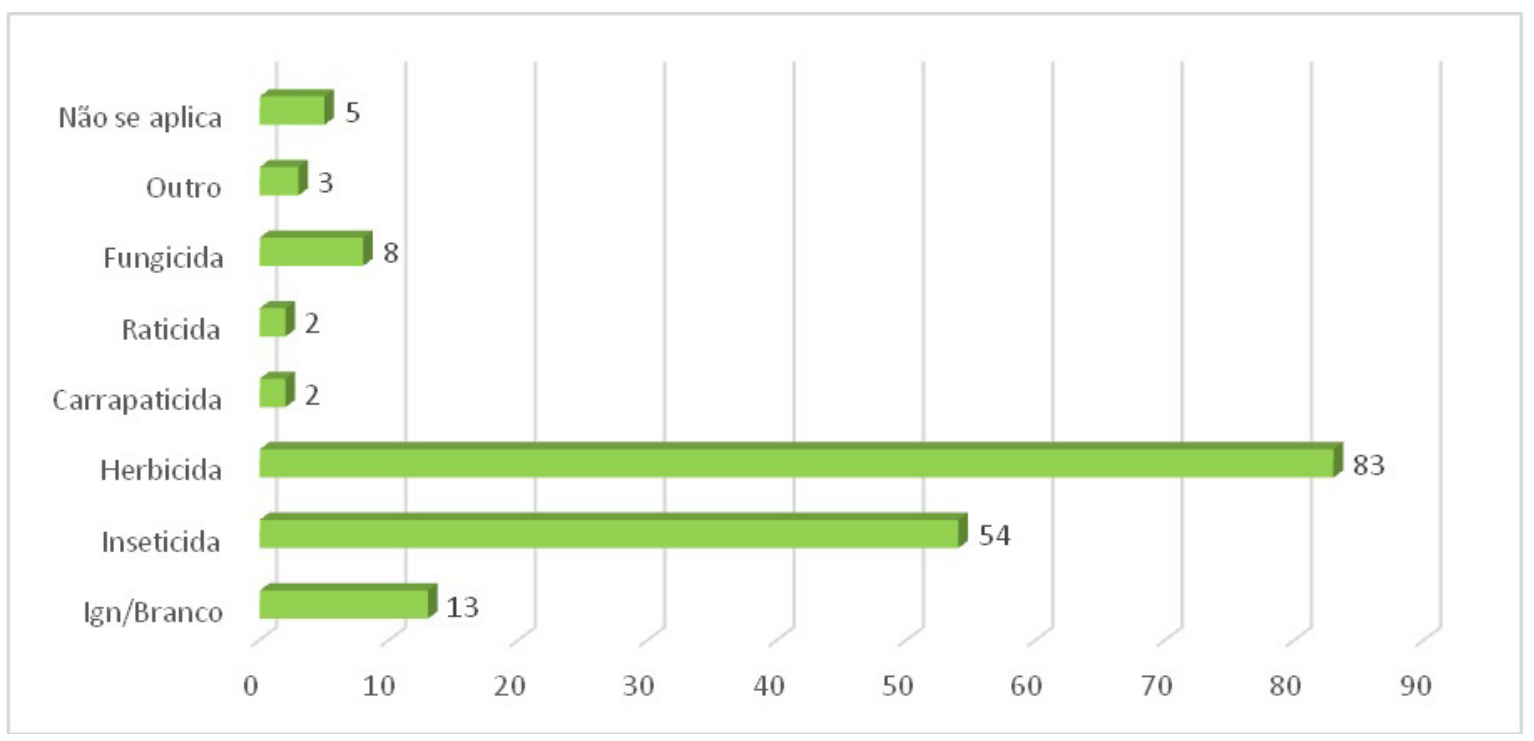

Fonte: Ministério da Saúde ${ }^{(4)}$

Nas intoxicações no Oeste do Paraná, agrotóxicos de uso agrícola responderam por $41,8 \%$ do total. Deve-se ressaltar a grande ocorrência, no Brasil, de sub-registro das intoxicações por agrotóxicos. Esta é uma das grandes vulnerabilidades do País, entre outras relacionadas ao controle e monitoramento do uso de agrotóxicos em todo o território nacional, e um aspecto a ser considerado nos processos de registro e reavaliação desses produtos técnicos. ${ }^{(19)}$

A Anvisa apresentou alterações nos critérios e procedimentos para o processo de reavaliação toxicológica. As informações para o preenchimento dos critérios foram obtidas a partir de referências internacionais de entidades como a Autoridade Europeia para Segurança Alimentar (European
Food Safety Authority - EFSA) e a Agência de Proteção Ambiental dos Estados Unidos (United States Environmental Protection Agency - US EPA). Foram usados dados do Programa de Análise de Resíduos de Agrotóxicos em Alimentos (PARA). Houve discussão entre diferentes órgãos, como o Ministério da Agricultura, Pecuária e Abastecimento (Mapa) e do Instituto Brasileiro do Meio Ambiente e Recursos Renováveis (Ibama), que também são responsáveis pelo registro de agrotóxicos no Brasil, além do Ministério da Saúde, Vigilâncias Sanitárias, Ministério Público Federal e associações da indústria de agrotóxicos também participaram. ${ }^{(20)}$

No Brasil, o registro de agrotóxicos não tem prazo de validade. Assim, uma vez que um produto 
entra no mercado, ele pode permanecer de forma indefinida. Por isso, a reavaliação é o instrumento técnico e legal para a revisão do perfil de segurança de produtos, a partir de novas informações produzidas pelos sistemas de monitoramento ou pesquisas científicas. De acordo com a Anvisa, a análise dos itens da lista pode levar ao banimento do produto ou pode mantê-lo em comercialização com medidas para reduzir o perigo decorrente do seu uso. A reavaliação também poderá levar à decisão de manter o produto em circulação sem nenhuma nova recomendação. Como no Brasil um agrotóxico novo só pode ser registrado em categoria toxicológica igual ou inferior a outro já existente no mercado, a reavaliação torna-se instrumento fundamental para a diminuição, ao longo do tempo, do padrão de toxicidade do País. ${ }^{(20)}$

Quando se refere à evolução do caso, a Tabela 4 demonstra que $96,46 \%$, ou 164 pacientes, tiveram a cura sem sequela, indicando, de forma geral sem maiores análises, que os atendimentos hospitalares estão ocorrendo de forma satisfatória, ou pelo menos agindo para evitar consequências maiores. Observa-se que $0,59 \%$, ou um paciente, apresentou cura com sequela, e $0,59 \%$, ou um paciente, foi a óbito.

Tabela 4 - Evolução do caso dos indivíduos notificados na ficha de investigação de intoxicações por agrotóxicos de uso agrícola em município do Oeste do Paraná.

\begin{tabular}{lcc}
\hline Evolução & FA & FR \\
\hline Ignorado & 3 & $1,77 \%$ \\
Cura sem sequela & 164 & $96,46 \%$ \\
Cura com sequela & 1 & $0,59 \%$ \\
Óbito & 1 & $0,59 \%$ \\
Perda de seguimento & 1 & $0,59 \%$ \\
Total & 170 & $100 \%$ \\
\hline
\end{tabular}

Fonte: Ministério da Saúde ${ }^{(4)}$

Em estudo na Bahia, verificou-se a evolução de cura sem sequelas em $59,8 \%$, a cura com sequela em $2,6 \%$, e em torno de $1,8 \%$ evoluiu a óbito por intoxicação. Houve perda de seguimento em $0,8 \%$ e $34,7 \%$ foram os contabilizados em branco. ${ }^{(21)}$

Considera-se que mesmo com $96,46 \%$ dos casos de evolução representando cura sem sequela é preciso pensar que, no caso dos trabalhadores, os mesmos continuam expostos aos riscos e podem apresentar novamente casos de intoxicações ou uma situação mais grave proveniente do uso dos agrotóxicos, já que o atendimento oferecido não modifica o processo e o ambiente de trabalho do mesmo, apenas direciona uma ação pontual.

A evolução de um quadro de intoxicação pode estar relacionada a vários fatores, sendo este fundamental para determinar a extensão do dano causado ao indivíduo. De outra maneira se tem que aspectos psicológicos dificilmente são questionados e representam uma sequela significativa, de maneira que o trabalhador que já apresentou caso de intoxicação teme que o episódio se repita. Este cultiva o medo da perda do emprego e consequentemente o comprometimento financeiro e das relações familiares, especialmente se for considerado que já vivenciam uma situação social desfavorecida e que exige cuidados tanto no âmbito da saúde como em questões de cunho social.

Para compreender melhor a evolução destas questões fáticas, além dos dados apresentados, é preciso assistir o trabalhador e suas famílias quando expostos a casos de intoxicação com acompanhamento por meio da Atenção Básica e da Vigilância Sanitária. Deve haver real acolhimento, 
fortalecendo a Rede de Atenção, para que a compreensão de saúde não seja reduzida somente ao episódio, e sim, esteja voltada a toda a situação biopsicossocial que envolve a comunidade.

No Brasil, os casos de intoxicação por agrotóxicos apresentam grande subnotificação e descentralização de informações, decorrentes de fatores diversos: dificuldade de acesso dos agricultores às unidades de saúde, inexistência de centros de saúde em regiões produtoras importantes, dificuldade de diagnóstico e de relacionar os problemas de saúde com a exposição a agrotóxicos, escassez de laboratórios de monitoramento biológico e inexistência de biomarcadores precoces e/ou confiáveis. Mesmo com as dificuldades presentes e as deficiências de registro, o Sistema Nacional de Informações Tóxico-Farmacológicas (Sinitox) e o Sistema de Informação de Agravos de Notificação (Sinan) são referências importantes. ${ }^{(22)}$

Referente à atuação dos profissionais da saúde, existe uma enorme dificuldade para diagnosticar, registrar e até mesmo encaminhar pacientes intoxicados por agrotóxicos, o que fragiliza o número de registros com o número real de intoxicações - a própria Organização Mundial da Saúde reconhece que, para cada caso registrado de intoxicação pelos agrotóxicos, há 50 não notificados. ${ }^{(23)}$

Almeja-se que com os dados de prováveis intoxicações agudas, crônicas e contaminação ambiental e alimentar, os municípios, complementando com suas informações socioeconômicas locais, poderão construir um mapa dos possíveis impactos gerados pelo uso dos agrotóxicos com localização das comunidades rurais e urbanas mais ou menos vulneráveis. Assim, com participação da representação dos trabalhadores e população espera-se implementar processos de conhecimento, discussão da situação sanitária e organização da sociedade para executar uma vigilância à saúde efetiva. ${ }^{(19)}$

Com isso, as mudanças esperadas estão além de sequelas visíveis. Elas perpassam por questionamentos e pelo comprometimento político social no processo de trabalho, para que mais do que a redução dos casos de intoxicações por agrotóxicos, se possa lutar por maior segurança e proteção para trabalhadores rurais e seus familiares, além de toda a população que encontra-se exposta.

\section{Conclusão}

O estudo concluiu que a maioria dos casos registrados de intoxicações ocorreu em indivíduos do sexo masculino. Com relação à faixa etária, a predominância da ocorrência de intoxicações se deu na faixa de 20 a 49 anos, período que compreende a população ativa e em idade reprodutiva, correspondendo ao apresentado em outros estudos. Destaca-se a população urbana como a mais relacionada aos casos de intoxicação.

Verificou-se que a maioria dos casos ocorreu em atividades que não estavam relacionadas ao trabalho, de maneira acidental ou por exposição habitual ao agrotóxico, e há ênfase para as tentativas de suicídio. Por sua vez, as vias de exposição mais envolvidas são as digestivas e as respiratórias, o que enfatiza a evidência de que as intoxicações estão associadas a acidentes.

Observou-se que a maioria dos indivíduos intoxicados possui baixa escolaridade, sendo possível associar a escolaridade como um indicador de condição social importante que pode ser associado como um efeito protetor de intoxicações relacionadas aos agrotóxicos.

A partir da análise dos dados, percebeuse que a intoxicação pelo uso dos agrotóxicos é um problema grave, não apenas de saúde, mas ambiental e social, sendo essencial o surgimento de novas discussões com o tema.

Por fim, ao analisar o perfil das intoxicações exógenas por agrotóxicos agrícolas foi possível detectar as fragilidades, tanto no preenchimento adequado no sistema dos dados de toxicovigilância, que corresponde a uma responsabilidade compartilhada por toda a equipe, como a necessidade de um acompanhamento efetivo dos casos para uma maior compreensão dos fatores envolvidos. 


\section{Referências}

1 Ferreira MLPC. A pulverização aérea de agrotóxicos no Brasil: cenário atual e desafios. R Dir Sanit. 2015;15:18-45.

2 Instituto Brasileiro de Geografia e Estatística. Indicadores de Desenvolvimento Sustentável: Brasil 2012. Rio de Janeiro: IBGE; 2012 (Estudos e Pesquisas. Informação Geográfica, 9).

3 Neves PDM, Bellini M. Intoxicações por agrotóxicos na mesorregião norte central paranaense, Brasil: 2002 a 2011. Ciênc Saúde Colet. 2013;18:3147-56.

4 Ministério da Saúde (BR). Intoxicação exógena: notificações registradas no Sinan Net - Paraná [Internet]. 2016 [citado 2016 jul 20]. Disponível em: http://tabnet.datasus.gov.br/cgi/deftohtm. exe?sinannet/cnv/Intoxpr.def

5 Dantas JSS, Uchôa SL, Cavalcante TMC, Pennafort VPS, Caetano JAC. Perfil do paciente com intoxicação exógena por "chumbinho" na abordagem inicial em serviço de emergência. Rev Eletr Enf [Internet]. 2013 [citado 2016 nov 15];15(1):54-60. Disponível em: https://www. fen.ufg.br/fen_revista/v15/n1/pdf/v15n1a06.pdf

6 Ministério da Saúde (BR). Cadernos de informação de saúde: Paraná [Internet]. 2016 [citado 2016 nov 15]. Disponível em: tabnet. datasus.gov.br/tabdata/cadernos/pr.htm

7 Prefeitura Municipal de Cascavel. Lei no 6505 de 07 de julho de 2015. Altera a lei $n^{\circ} 6484 / 2015$, que regulamenta o uso e aplicação de agrotóxicos próximos aos locais que especifica no município de Cascavel, e dá outras providências. Cascavel: Prefeitura Municipal; 2015.

8 Marconi MA, Lakatos EM. Fundamentos de metodologia científica. São Paulo: Atlas; 2011.

9 Malaspina FG, Zinilise ML, Bueno, PC. Perfil epidemiológico das intoxicações por agrotóxicos no Brasil, no período de 1995 a 2010. Cad Saúde Colet. 2011;19(4):425-34.

10 Nóbrega HOS, Silva EL, Mariz SR, Bragagnolli G, Fook SML. Perfil das intoxicações notificadas na paraíba, de 2009 a 2013. Rev Cereus. 2015;7(2).
11 Neves PDM, Bellini M. Intoxicações por agrotóxicos na mesorregião norte central paranaense, Brasil: 2002 a 2011. Ciênc Saúde Colet. 2013;18(11):3147-56.

12 Dutra RMS, Souza MMO. Impactos negativos do uso de agrotóxicos a saúde humana. Hygeia. 2017;13(24):127-40.

13 Casali AL, Schlosser JF, Gandolfo MA, Uhry D, Rodrigues FA. Nível de capacitação e informação dos operadores de máquinas para a aplicação de agrotóxicos. Ciênc Rural [Internet]. 2015 [citado 2019 jan 1];45(3):42531. Disponível em: http://www.scielo.br/pdf/cr/ v45n3/0103-8478-cr-00-00-cr-20121099.pdf

14 Murakami Y, Pinto NF, Albuquerque GSC, Perna PO, Lacerda A. Intoxicação crônica por agrotóxicos em fumicultores. Saúde Debate. 2017;41(113):563-76.

15 Martins MKS, Cerqueira GS, Sampaio AMA, Lopes AA, Freitas RM. Exposição ocupacional aos agrotóxicos: um estudo transversal. Revinter. 2012;5(3):6-27.

16 Mascarenha TKSF, Pessoa YSRQ. Aspectos que potencializam a contaminação do trabalhador rural com agrotóxicos: uma revisão integrativa. Trab Educ. 2013;22:87-103.

17 Instituto Nacional de Câncer. Estimativa 2018: incidência de câncer no Brasil. Rio de Janeiro: INCA; 2017.

18 Instituto Brasileiro de Geografia e Estatística. Pesquisa nacional por amostra de domicílios 2001 a 2013 [Internet]. 2013 [citado 2014 jan 5]. Disponível em: http://www.sidra.ibge.gov. br/pnad/pnadpb.asp

19 Carneiro FF, Friedrich K, Rigotto RM, Augusto LGS, Búrigo AC. Dossiê ABRASCO: um alerta sobre os impactos dos agrotóxicos na saúde. Rio de Janeiro: EPSJV; 2015.

20 Agência Nacional de Vigilância Sanitária. Resolução da diretoria colegiada - RDC $\mathrm{n}^{\mathrm{o}}$ 221, de 28/03/2018 [Internet]. 2018 [citado 2019 maio 25]. Disponível em: http://portal. anvisa.gov.br/legislacao\#/visualizar/371441 
21 Alcântara NDF; Fernandes HMB, Oliveira Filho AA. Avaliação das intoxicações no estado da Bahia: um estudo epidemiológico. Biofarm. 2013;9(1):160-6.

22 Cassal VB, Azevedo LF, Ferreira RP, Silva DG, Simão RG. Agrotóxicos: uma revisão de suas consequências para a saúde pública. REGET. 2014;18(1):437-45.

23 Pedroza EHO. O uso indiscriminado de agrotóxicos e a violação dos direitos fundamentais à alimentação saudável, à saúde e ao meio ambiente equilibrado e suas consequências ao cofre da seguridade social. Justiça Direito. 2013; 27(1):220-33. 
Frizon, E. et al. 